\title{
Recommendations for assessing motor performance in individuals with dementia: suggestions of an expert panel - a qualitative approach
}

Sandra Trautwein ${ }^{1 *} \mathbb{D}$, Bettina Barisch-Fritz ${ }^{1}$, Andrea Scharpf ${ }^{1}$, Willem Bossers², Marcus Meinzer ${ }^{3,4}$, Simon Steib ${ }^{5}$, Thorsten Stein ${ }^{1}$, Klaus Bös ${ }^{1}$, Alexander Stahn ${ }^{6,7}$, Claudia Niessner ${ }^{1}$, Stefan Altmann ${ }^{1}$, Rita Wittelsberger ${ }^{1}$ and Alexander Woll ${ }^{1}$

\begin{abstract}
Background: Recommendations for assessing motor performance in individuals with dementia (IWD) are rare, and most existing assessment tools previously applied in IWD were initially developed for healthy older adults. However, IWD and their healthy counterparts differ in motor and cognitive capabilities, which needs to be considered when designing studies for this population. This article aims to give recommendations for motor assessments for IWD and to promote standardisation based on a structured discussion of identified assessment tools used in previous trials.

Methods: Appropriateness and standardisation of previously applied motor assessments for IWD were intensively discussed using a qualitative approach during an expert panel. Furthermore, the use of external cues and walking aids, as well as psychometric properties were considered. Starting with a comprehensive overview of current research practice, the discussion was gradually specified and resulted in the elaboration of specific recommendations.
\end{abstract}

Results: The superior discussion emphasised the need for tailoring motor assessments to specific characteristics of IWD and attaching importance to standardised assessment procedures. Specific recommendations include the use of sequential approaches, which incorporate a gradual increase of complexity from simple to more difficult tasks, a selection of motor assessments showing sufficient relative reliability and appropriateness for IWD, as well as allowing external cues and walking aids when restricted to repeated instructions and commonly used devices, respectively.

Conclusions: These are the first recommendations for assessing motor performance in IWD based on a comprehensive qualitative approach. Due to limited evidence, it was not possible to address all existing questions. It is therefore important to evaluate these recommendations in studies with IWD. Besides tailoring and evaluating available assessments, future research should focus on developing specific tools for IWD. Moreover, further progress in standardisation is necessary to enhance comparability between different trials. This article provides initial approaches for overcoming existing limitations in trials with IWD by giving recommendations and identifying future research questions, and therefore contributes to enhancing evidence regarding efficacy and effectiveness of physical activity interventions.

Keywords: Dementia, Physical activity, Exercise, Motor performance, Motor assessments

\footnotetext{
* Correspondence: sandra.trautwein@kit.edu

'Institute of Sports and Sports Science, Karlsruhe Institute of Technology,

Engler-Bunte-Ring 15, 76131 Karlsruhe, Germany

Full list of author information is available at the end of the article
}

(c) The Author(s). 2019 Open Access This article is distributed under the terms of the Creative Commons Attribution 4.0 International License (http://creativecommons.org/licenses/by/4.0/), which permits unrestricted use, distribution, and reproduction in any medium, provided you give appropriate credit to the original author(s) and the source, provide a link to the Creative Commons license, and indicate if changes were made. The Creative Commons Public Domain Dedication waiver (http://creativecommons.org/publicdomain/zero/1.0/) applies to the data made available in this article, unless otherwise stated. 


\section{Background}

Designing studies to investigate the efficacy and effectiveness of physical activity on motor and cognitive performance in individuals with dementia (IWD) is challenging. Despite increasing research in this area [1], there still is insufficient evidence, which can be explained by methodological limitations, unspecific interventions, or inappropriate assessments [2-4]. This emphasises the need for further high quality studies guided by suggestions for optimised interventions and sensitive assessment tools.

Previous trials which aimed at improving motor performance in IWD frequently applied interventions and assessment tools not adapted to the target population [2, 5]. Considering significant differences in cognitive and motor performance [6-10], however, it is not possible to directly translate study designs developed for healthy older adults to IWD. Especially interventions and assessments need to be tailored to the specific characteristics of IWD, such as decreased executive functioning, reduced attentional and memory capacities [6, 7], diminished ability to develop and perform new complex motor sequences [11], and impaired gait and balance performance $[8,10]$. For motor assessments, it is important to consider these cognitive and motor impairments, as both aspects hamper a successful participation. Besides research, this is also important for clinical practice considering prognostic, diagnostic, and therapeutic reasons $[12,13]$.

Due to cognitive impairment, IWD are often not able to concentrate on comprehensive or complex, unknown tasks, and frequently show difficulties in comprehending instructions, developing appropriate motor actions, and remembering these during execution [11]. Considering this, there are indications that cognitive impairment may influence the outcome of motor assessments and compromise their feasibility [14]. Appropriate assessments therefore need to be tailored to cognitive impairments. It has been suggested that assessments should be of short duration, use appropriate instructions (e.g. no verbal focus, demonstration of the task, clear, short, and repeated instructions [11]), and include simple motor tasks. Moreover, previous studies discuss the use of external cues thereby considering decreased cognitive abilities. For example, van Iersel et al. [15] emphasise the need for external cues, which are required to ensure feasibility and to achieve high relative reliability. In contrast, Hauer et al. [11] argue that external cues could influence the results and possibly reflect speed, reliability, and quality of external cues rather than actual performance of IWD.

Considering motor influences, disease-specific gait and balance impairments are often accompanied by age-related degeneration, such as frailty [16]. Together, they frequently compromise the ability of IWD to walk independently, to complete more complex balance tasks, and to cover longer distances [10, 17], which are necessary to participate in many assessments. Thus, appropriate assessments also need to be tailed to motor impairments. In this context, it is important to discuss the use of walking aids during assessments. IWD are frequently dependent on walking aids [15], which ensure participants' safety. However, an investigation in geriatric patients without or with mild to moderate cognitive impairment found that walking aids impede the detection of gait or mobility deficits and thus adversely affect identifying changes over time [18].

Furthermore, the significance of assessments depends on sound psychometric properties, which are necessary to draw meaningful conclusions [5]. Investigations determining psychometric properties of motor assessment tools in IWD are rare, especially concerning validity [19]. Considering test-retest reliability, intraclass correlation coefficients ranging between .42 and .99 and high intra-individual variability were found for most previously applied assessment tools, indicating fair to excellent relative reliability but insufficient absolute reliability $[15,20-30]$. Summarising these results, it has been concluded that the considered motor assessments are appropriate for detecting inter-individual differences in cross sectional or controlled intervention studies, whereas the intra-individual variability was too large to be suitable for investigating intra-individual performance changes [20, 21].

Considering all above-mentioned aspects leads us to the question which motor assessments are actually appropriate for IWD. Unfortunately, there is currently a lack of recommendations or guidelines on how to assess motor performance in IWD. In two of the few studies addressing this issue, Bossers et al. [19] and McGough et al. [31] performed a systematic and scoping review, respectively, and recommended using the Berg Balance Scale, the Performance Oriented Mobility Assessment, the Timed Up \& Go Test (TUG), short distance walk tests (WT), sit-to-stand (STS) tests, isometric strength assessments, and the 6-min WT for IWD in mild to moderate stages of the disease. Both research groups derived their recommendations based on frequency of use and observed outcome effect sizes in previous trials. They also considered investigations of psychometric properties. However, the authors noted large heterogeneity in the assessment tools used across trials and indicated that insufficient information about feasibility, sensitivity to change, and psychometric properties was frequently provided.

These systematic reviews provide first indications for appropriate motor assessment tools for IWD. However, these recommendations predominantly concern quantitative aspects, and subsequently do not sufficiently consider specific characteristics. There are no comprehensive 
qualitative approaches focusing on tailoring motor assessments to IWD.

Besides tailoring motor assessments to the specific characteristics of IWD, their standardisation is also important. Gonçalves et al. [4] note that large heterogeneity in outcomes and assessment tools limits evidence of the efficacy and effectiveness of physical activity in IWD. A detailed review of previous trials also shows that different variations of motor assessment tools were used, which hampers comparability. This emphasises the urgent need to standardise existing motor assessments used in IWD.

This article describes the outcome of a consensus meeting of an international expert panel that aimed to derive recommendations for assessing motor performance in IWD. Due to limited information available for appropriate assessments and their standardisation, the specific goals of the panel were:

1. To discuss the selection of appropriate existing motor assessments, and the standardisation of assessment procedures.

2. To develop standards and procedures for using external cues and walking aids during assessments.

3. To examine psychometric properties of recommended assessments.

\section{Methods}

\section{Organisation and participants of the expert panel}

The international expert panel was organised by, and held at the Karlsruhe Institute of Technology (KIT) at the Institute of Sports and Sports Science (Karlsruhe, Germany). It was composed according to two main aspects: interdisciplinary variety and practical relevance. Interdisciplinarity and methodological variety was achieved by inviting researches from motor and cognitive sciences as well as the humanities, social, and natural sciences. Practical relevance was obtained by involving researchers with direct experience in the development and evaluation of motor assessments or with experience in dementia research. The initial group invited to this expert panel comprised 27 international researchers, who were chosen based on existing relations with the KIT and a literature screening aimed to identify researchers located within geographical proximity who were interested in motor assessments in IWD.

The expert panel consisted of two interrelated one-day meetings, aiming to achieve an iterative structure. At the first meeting in December 2014, the participants were twelve researchers from five institutions in two countries (Germany and Australia) in the disciplines sports science (especially focusing on biomechanics, human movement science, motor control and learning, sports psychology, sports therapy, and training science), movement and sport gerontology, and psychology. The second meeting in February 2015, comprised a group of five researchers from Germany and the Netherlands covering the disciplines sports science (especially focusing on biomechanics, human movement science, sports therapy, and training science), as well as movement and sport gerontology. With one exception, all researchers of the second meeting also participated in the first. More information on participating researchers is given in the declaration section (see Authors' information).

Discussion and guiding questions during the expert panel Prior to the first meeting, the host institution (KIT) elaborated guiding questions based on challenges in assessing motor performance in IWD identified by literature review. These questions included aspects of appropriateness and standardisation of motor assessments used in previous trials with IWD, use of external cues and walking aids during assessments, and psychometric properties of the considered tools (see Table 1). To enable these guiding questions to be discussed, the KIT research group presented an introductory overview of current research practises and participating researchers introduced their own research experiences with IWD at the first meeting. The discussion was stimulated by the research team of the host institution and one participating researcher supported its guidance.

The first meeting focused on the appropriateness of available motor assessments. In a first step, specific characteristics of IWD and derived demands for motor assessments were considered. Subsequently, these demands were applied to motor assessment tools used in previous trials, which were identified in randomised controlled trials initially analysed for a systematic review assessing effects of physical activity on motor and cognitive performance in IWD [32], supplemented by studies of Bossers et al. [33-35] (see Table 2). Each tool was then rated whether it sufficiently considered specific characteristics of IWD or could be tailored to them. Specific criteria that impacted this evaluation were duration, instructions, and complexity of each assessment tool, as well as physical strains caused in participants. To address standardisation, descriptions and variations of identified motor assessments were considered and possible modifications were discussed. The discussion concerning the use of external cues and motor assessments focused on the two contrary points of view identified in literature: their need to ensure feasibility and safety vs. the influence of external cues and walking aids on the results of motor assessments. Finally, psychometric properties of the identified motor assessments were considered based on available investigations.

The discussion of all guiding questions was gradually specified from open brain storming to personal estimations and final feedback rounds. Thereby, advantages 
Table 1 Guiding questions for the discussion during the expert panel

\begin{tabular}{ll}
\hline Appropriateness and standardisation & Guiding questions \\
& Are existing motor assessments appropriate for investigating motor performance in IWD? \\
& Which motor assessments can be recommended for IWD? \\
Use of external cues and walking aids & Should the use of external cues during motor assessments in IWD be allowed or not? \\
& If yes, which kind of external cues should be allowed? \\
& How can external cues be standardised? \\
& Should the use of walking aids be allowed during motor assessments in IWD or not? \\
& If no, what if IWD are not able to perform task without? \\
& If yes, which kind of walking aids should be allowed? \\
Psychometric properties & Are existing motor assessments valid and reliable to investigate motor performance in IWD?
\end{tabular}

IWD Individuals with dementia

and disadvantages of individual assessment tools and general procedures were gathered and discussed. In doing so, the first meeting elaborated a comprehensive decision basis for the second meeting and developed specific questions for each assessment tool.

Based on the results of the first meeting, the second meeting aimed to derive specific recommendations in a smaller group setting. It started with a summary of the results, which were then examined based on common research practice and own research experiences. In the next step, guiding questions were again critically reflected and specific questions for each assessment tool were discussed in detail. As described above, the discussion again was gradually specified. Finally, the appropriateness of assessment tools and use of external cues and walking aids was established by voting. Consensus was defined as an $80 \%$ majority. If consensus was not directly reached, another discussion round was started.

\section{Results}

The discussion on current research practices and experiences resulted in a consensus for applying a sequential approach to assess motor performance in IWD. This means that the level of difficulty is gradually increased, starting with simple and proceeding to more complex tasks, if possible. Such an approach takes specific characteristics and needs of the target population into account, and also considers their heterogeneity and reduced physical capacity. This guarantees appropriate requirements tailored to individual performance and improves the feasibility of assessments and comparability of results. For the further discussions, this sequential approach was supposed to be a basic assumption.

\section{Recommendations for appropriateness and standardisation of motor assessments}

Estimating the appropriateness of motor assessments was performed separately for different physical domains: balance, mobility and gait, strength, endurance, flexibility, and functional performance. To ensure a clear understanding of assessments, short descriptions are given in Table 2.
Based on several underlying considerations extensively described in the following sections, the discussion resulted in recommending the motor assessments summarised in Table 3. As the selection of outcomes and assessments depends on specific objectives and the framework of investigations or aims of clinical examinations, we do not recommend a fixed assessment battery but rather propose a possible selection. Hence, several alternatives are given in Table 3. When composing an assessment battery, it is of great importance to consider the limited capacity of IWD. Thus, we advise restricting the maximum duration of assessments, including rests, to $60 \mathrm{~min}$.

\section{Balance assessments}

To investigate balance, previous trials applied static (one-leg balance test [36], single leg stance, Frailty and Injuries: Cooperative Studies of Intervention Technique - subtest 4 (FICSIT-4) [37], posturography platforms, and Functional Reach Test [38]) and dynamic approaches (Figure of Eight Test [39] and Groningen Meander Walking Test (GMWT) [27]). They also utilised balance scales (Berg Balance Scale [40] and Performance Oriented Mobility Assessment [41]) encompassing both static and dynamic tasks.

To assess static balance, we recommend the FICSIT-4. Compared to one-leg balance tests, this assessment fulfils the requirement of a sequential approach, starting with a less demanding postural position (parallel stance) which is gradually increased (semi-tandem, tandem, and one-leg stance). Assessment tools recording postural sway, like posturography platforms or force plates, can provide more precise information on static balance. However, many of these assessments cannot be recommended for IWD, since they overtax their physical and balance capabilities. In this context, Ruhe et al. [42] performed a systematic review considering various ages and health groups and suggested that three to five repetitions of $90 \mathrm{~s}$ each are necessary to reach acceptable reliability values for centre of pressure sway measures. Based on our own 
Table 2 Selection of motor assessments ${ }^{\mathrm{a}}$ discussed in the expert panel

\begin{tabular}{lll}
\hline Assessments & $\begin{array}{l}\text { Outcomes assessed in } \\
\text { previous trials }\end{array}$ & Description \\
\hline
\end{tabular}

Balance

Static balance assessments

One-leg balance test [36]

Single leg stance

Frailty and Injuries: Cooperative Studies of Intervention Technique subtest 4 [37]

Posturography platforms assessing postural sway

Functional Reach Test [38]

Dynamic balance assessments

Figure of Eight Test [39]

Groningen Meander Walking Test [27]

Balance scales

Berg Balance Scale [40]

Performance Oriented Mobility Assessment [41]

Mobility and gait

Get up \& go tests

Get-Up and Go Test [44]

Timed Up \& Go Test [47]

8-ft up-and-go test [54]

Manual Timed Up \& Go Test $[76,77]$

Cognitive Timed Up \& Go Test [77]

Walk tests / instrumented gait analysis

6-m walk test [45]

10-m walk test [45]

Not specified [68]
Balance, dynamic walking ability [34]

Balance [68]

Lower leg strength and balance [69]

Balance, static balance $[33,34]$

Balance [70]

Balance and stability [71]

Balance, dynamic balance $[33,34]$

Functional balance, balance impairment $[69,72,73]$

Gait and balance [74, 75]

Mobility, functional mobility, balance, dynamic balance, locomotion, muscle-nerve coordination, agility $[33,34,70-74]$

Speed, agility, and balance while moving [75]

Mobility [73]

Mobility [73]

Mobility, walking speed [33, 34, 68]

Walking speed [70]
Standing on one leg while participants' ability to maintain this stance for $5 \mathrm{~s}$ is recorded.

Standing on a single leg alternately for $60 \mathrm{~s}$ with both eyes open and closed while time is recorded.

Performing four different stances for $10 \mathrm{~s}$ while participants' ability to maintain these stance is evaluated: (1) feet together, (2) semi-tandem, (3) tandem, (4) single-leg.

Standing quietly on a posturography platform for $60 \mathrm{~s}$ with eyes open while elliptical area covered by moving centre of gravity is recorded.

Standing next to a wall, holding one arm parallel to a metre stick attached to the wall at shoulder height, and reaching forward as far as possible without losing balance or changing foot position, while distance from starting to end position is recorded.

Walking a lap of a standard figure-eight trajectory as quickly and accurately as possible while walking speed and number of oversteps are recorded.

Walking over a meandering curved line as quickly and accurately as possible while time and number of oversteps are recorded. Use of a walking aid is allowed.

14-item functional balance assessment with simple everyday tasks (reaching, bending, transferring, standing and rising) which are graded on a five-point ordinal scale (0 to 4 ).

Scale with two parts, assessing balance (sitting balance, rising from a chair and sitting down, standing balance with eyes open then closed, and turning balance) and gait (gait initiation, step length and height, symmetry, continuity, path direction, and trunk sway).

Standing up from a chair, walking $3 \mathrm{~m}$, turning around, walking back to the chair, and sitting down, while performance is evaluated from 1 to $5(1=$ no instability to $5=$ very abnormal). Use of a walking aid is allowed.

Standing up from a chair, walking $3 \mathrm{~m}$, turning around, walking back to the chair, and sitting down, while time is measured. Use of a walking aid is allowed.

Standing up from a chair, walking $8 \mathrm{ft}$, turning around, walking back to the chair, and sitting down, while time is measured.

Timed Up \& Go Test with additional manual task (carrying a glass of water).

Timed Up \& Go Test with additional cognitive task (counting backwards by threes).

Walking $6 \mathrm{~m}$ with comfortable pace while time is recorded. Use of walking aid is allowed.

Walking $10 \mathrm{~m}$ with comfortable pace while time is recorded. Use of walking aid is allowed. 
Table 2 Selection of motor assessments ${ }^{\mathrm{a}}$ discussed in the expert panel (Continued)

\begin{tabular}{cll}
\hline Assessments & $\begin{array}{l}\text { Outcomes assessed in } \\
\text { previous trials }\end{array}$ & Description \\
\hline Instrumented gait analysis [46, 78] & $\begin{array}{l}\text { Walking speed, stride length, } \\
\text { double limb support time [79] }\end{array}$ & $\begin{array}{l}\text { Walking at a comfortable pace over an electronic walkway while } \\
\text { spatiotemporal gait parameters are recorded. }\end{array}$
\end{tabular}

Strength

\section{Sit-to-stand tests}

Five Times Sit-to-Stand Test [52]

30-s chair-stand test [55]

Modified 30-s chair-stand test, use of upper limbs allowed [20,55]

Stair-climbing performance [53]

\section{Instrumented assessments}

Maximal isometric strength assessed with dynamometers [80]

One-repetition maximum in leg press

Upper limbs strength

Handgrip dynamometer

Arm curl test [54]

Endurance

Walk tests

2-min walk test [61]

6-min walk test [62]

Modified 6-min walk test, use of walking aids allowed [23]

2-min step test [54])

Flexibility

Chair sit-and-reach test [54]

Back scratch test [54]

\section{Functional performance}

(Modified) Short Physical Performance Battery [63]
Lower extremity muscle strength and muscle endurance $[71,74]$

Muscle dynamic strength endurance of legs [75]

Lower body strength, leg strength $[33,34]$

Functional performance [74]

Maximal isometric muscle strength, maximal knee extension strength $[33,34,74]$

Maximal dynamic concentric muscle strength in hip and knee extensors [74]

Handgrip strength [74]

Muscle dynamic strength endurance of upper body [75]

Ambulation [81]

Walking performance [82]

Walking endurance, functional mobility [33, 34, 83]

Aerobic endurance [75]

Flexibility, flexibility of lower body $[70,75]$

Flexibility of upper body [75]

Functional performance [74]

Functional capacity [75]
Performing five repetitions of the sit-to-stand task without upper extremity assistance while time is recorded.

Performing as many repetitions of the sit-to-stand task as possible within $30 \mathrm{~s}$ with arms folded across chest.

Performing as many repetitions of sit-to-stand task as possible within $30 \mathrm{~s}$ with upper extremity assistance.

Climbing a flight with 13 stairs while time is recorded.

Pushing as hard as possible against the dynamometer after adopting a standardised position while maximum strength and integral over time are recorded.

One-repetition maximum as achieved in the leg-press training machine.

Putting maximum force on a dynamometer while maximal handgrip strength is recorded.

Performing as many biceps curls as possible within $30 \mathrm{~s}$ holding a hand weight of 5 pounds (women) / 8 pounds (men).

Walking for 2 min while distance is recorded. Use of usual walking aids is allowed.

Walking for 6 min without use of walking aids while distance is recorded.

Walking for 6 min while distance is recorded. Use of usual walking aids / physical assistance is allowed.

Performing as many full steps as possible within 2 min, raising knees to a point midway between the patella and iliac crest.

Stretching one leg keeping heel on the floor and trying to touch the toes with the fingers while sitting on a chair while distance between the fingers and toes is recorded.

Reaching over the shoulder with one hand and up the middle of the back with the other hand while the distance between extended middle fingers is recorded.

Assessment battery with three subtests including standing balance (tandem, semi-tandem, and side-by-side stands), walking speed over an 8-ft walking course, and Five Times Sit-to-Stand Test, which are graded on a five-point ordinal scale (0 to 4 ).

The modified version comprises two subtests including the Five Times Sit-to-Stand Test and gait performance (maximum walking speed, step frequency, cadence).

Assessment battery including

(1) 30-s chair stand and arm curl test,

(2) chair sit-and-reach and back scratch test,

(3) 8-ft up-and-go test, and

(4) 2-min step test 
Table 2 Selection of motor assessments ${ }^{a}$ discussed in the expert panel (Continued)

\begin{tabular}{|c|c|c|}
\hline Assessments & $\begin{array}{l}\text { Outcomes assessed in } \\
\text { previous trials }\end{array}$ & Description \\
\hline Physical Performance Test [53] & $\begin{array}{l}\text { Performance based motor } \\
\text { function activities of daily } \\
\text { living [35] }\end{array}$ & $\begin{array}{l}\text { Assessment battery with seven items (writing a sentence, } \\
\text { simulated eating, lifting a book onto a shelf, putting on a } \\
\text { jacket, picking up a coin from the floor, walking } 50 \mathrm{ft} \text {, and } \\
\text { turning } 360^{\circ} \text { ), which are scored on a 4-point Likert scale. }\end{array}$ \\
\hline $\begin{array}{l}\text { Erlangen Test of Activities of } \\
\text { Daily Living [64] }\end{array}$ & $\begin{array}{l}\text { Performance based } \\
\text { activities of daily living [35] }\end{array}$ & $\begin{array}{l}\text { Assessment battery with five items (pouring a drink, spreading } \\
\text { and cutting a sandwich, opening a small cupboard with a } \\
\text { key, washing hands, and tying a bow on a present), which } \\
\text { are rated according to correctly performed substeps ( } 0-6 \text { points). }\end{array}$ \\
\hline
\end{tabular}

${ }^{a}$ Motor assessments displayed in Table 2 were identified in trials initially analysed for a review assessing effects of physical activity on motor and cognitive performance in IWD [32], supplemented by studies of Bossers et al. [33-35]

experiences, we thus queried feasibility for the majority of IWD. The same applies for the Functional Reach Test. Assuming a non-satisfactory execution, like not leaning forward as far as possible due to fear of falling [43], we concluded that the Functional Reach Test is not a valid assessment for static balance in IWD.

The Figure of Eight Test and the GMWT both assess dynamic balance by determining speed and accuracy while walking a prescribed course - a figure of eight trajectory and a meandering curved line, respectively. Compared to the Figure of Eight Test, the walking course of the GMWT was simplified and thereby tailored to the specific characteristics of IWD [27]. Therefore, we recommend using the GMWT to assess dynamic balance in IWD.

Compared to single balance assessments, balance scales like the Berg Balance Scale or the Performance Oriented Mobility Assessment include various items predominately focusing on important tasks for everyday life. With small restrictions concerning the tasks of leaning forward and one-leg stance, all items seem to be feasible for IWD. Thus, we consider both balance scales appropriate to use with IWD. Even though these scales evaluate balance more comprehensively than single assessments, their longer duration needs to be considered. Therefore, we recommend balance scales for investigations or clinical examinations focusing on balance, but suggest using single assessments in trials and clinical examinations investigating various physical domains.

\section{Mobility and gait assessments}

Common mobility and gait assessments in IWD include get up and go tests [44], WT [45], and gait analyses [46]. All of these assessments are of short duration, apply simple instructions, and include familiar tasks from everyday life. Based on these estimations, we recommend using all three types of mobility and gait assessments for IWD. However, different variations of get up and go tests and WT exist why standardisation of assessment procedures is very important.

Regarding get up and go tests, different versions vary concerning scoring methods and walking distances. The TUG, a get up and go test version introduced by Podsiadlo and Richardson [47], allows a quantitative evaluation through timing and is also the most frequently used approach. We therefore recommend using this version of get up and go tests. However, the TUG and other available get up and go test versions consist of various short tasks, which need to be remembered during execution. Thus, the appropriateness of the TUG for IWD is somewhat limited and predominantly applies for IWD in mild stages of the disease or tailored approaches allowing the use of external cues (see below).

There are WT for different walking distances and paces. Considering spatial limitations and relevance for

Table 3 Recommended motor assessments

\begin{tabular}{ll}
\hline Outcome & Assessments \\
\hline Balance & Frailty and Injuries: Cooperative Studies of Intervention Technique - subtest 4 [37] \\
& Groningen Meander Walking Test [27] \\
& If the investigation/clinical examination focuses on balance: Berg Balance Scale [40] or Performance \\
& Oriented Mobility Assessment [41] \\
& Timed Up \& Go Test [47] \\
Mobility and gait & -m walk test [45] \\
& Instrumented gait analysis (GAITRite ${ }^{\circledast}$, comfortable pace, single and dual tasks) [46] \\
Lower limb strength & Modified 30-s chair-stand test [20, 55], including time for five repetitions \\
Endurance & With constraints, if endurance is an important outcome: 2-min walk test [61] or 6-min walk test [62] \\
Functional performance & Short Physical Performance Battery [63] \\
& Physical Performance Test [53] \\
\hline
\end{tabular}


short distance walking situations in everyday life, we recommend assessing walking at a comfortable pace over a course of six metres. Instrumented gait analysis systems, such as GAITRite (CIR Systems Inc., Franklin, NJ), can be valuable in providing further detailed information on different spatiotemporal gait parameters. Additionally, dual task conditions can reveal interactions between cognition and gait more clearly $[48,49]$. Besides GAITRite ${ }^{\circ}$, which is widely used and has been successfully applied in IWD [50, 51], other instrumented gait analysis systems also might be appropriate, but rarely have been investigated in IWD.

\section{Strength assessments}

Concerning strength outcomes, available tools can be classified as lower limb (STS tests [52], stair-climbing performance [53], and instrumented strength assessments) or upper limb strength assessments (handgrip dynamometers and arm curl test [54]).

For lower limb strength, we recommend STS tests, in particular a modified 30-s chair-stand test, which allows the use of armrests $[20,55]$. Although STS performance only partly depends on lower limb strength $[56,57]$ and using armrests reduces knee and hip moments [58], it is a functional task, which is of high relevance for everyday life. Moreover, many IWD show reduced physical capacity, and thus may not be able to perform the task without the use of armrests. Compared to the Five Times Sit-to-Stand Test, which records the time required to perform five repetitions, the modified 30-s chair-stand test counts the number of repetitions within $30 \mathrm{~s}$ and fulfils the criteria of a sequential approach by allowing each participant to be rated independently of the number of STS repetitions. Additionally, the time required for five repetitions can be simultaneously assessed for all participants reaching this threshold. However, we do not recommend other lower limb strength assessments without constraints. Although stair-climbing performance is a clinically relevant measure of leg power [59], its feasibility may be compromised by practical (availability of standardised flight of stairs) and safety (risk of falling) reasons. With regard to instrumented strength assessments (e.g. dynamometers, isokinetic tools, fitness machines, or other apparatus assessing weights), it has been suggested that such assessments are generally too complex and impractical for assessing large groups [60]. Moreover, their suitability for IWD is questionable, as task-specific strength assessments are partly based on complex motion sequences, which are not related to everyday motor experiences, and therefore conflict with the decreased ability to develop and perform new or complex motor sequences of IWD [11].

We cannot recommend any of the available assessments for upper limb strength without constraints.
Dynamometers assessing handgrip strength were scarcely applied in IWD and first need to prove feasibility. The arm curl test was deemed unsuitable for IWD, because it involves a motion sequence unrelated to everyday life (see instrumented strength assessments).

\section{Endurance assessments}

The 6- or 2-min WT [61, 62], as well as the 2-min step test from the Senior Fitness Test (SFT) [54] are available for endurance assessments. We do not recommend these assessments without constraints. All assessments require participants to stand or walk for two or six minutes, respectively. In contrast, IWD often suffer from multiple motor impairments, frequently affecting the performance of standing or walking. Thus, available endurance assessments seem unsuitable for IWD. Consequently, we suggest limiting the use of such assessments only if specifically indicated by the study design or aim of clinical examination. Nonetheless, developing novel, feasible endurance assessments for frail IWD and examining feasibility of existing assessments well-established in other populations, such as ergometer tests, are indicated.

\section{Flexibility assessments}

Only few previous investigations have incorporated flexibility assessments in IWD. Accordingly, the discussion did not consider flexibility assessments in detail. Examples are the chair sit-and-reach test, as well as the back scratch test from the SFT [54]. As information on their feasibility in IWD is scarcely available, we suggest not using these flexibility assessments, unless flexibility is a central outcome measure.

\section{Functional performance assessments}

Looking at functional performance assessments, previous trials applied the Short Physical Performance Battery [63], the Physical Performance Test [53], the Erlangen Test of Activities of Daily Living [64], and the SFT [54]. Among these, Freiberger et al. [65] recommend both the Short Physical Performance Battery and the Physical Performance Test for unimpaired older adults. Both assessments apply tasks relevant to everyday life (e.g., simulated eating, putting on a jacket, standing up from a chair, and walking), and previous trials have demonstrated feasibility in IWD. Thus, our recommendation is to include both assessments to assess functional performance in IWD.

The Erlangen Test of Activities of Daily Living, specifically developed for IWD, is easy and short to administer and includes tasks demonstrating relevance for everyday life (e.g. pouring a drink or washing hands) [64]. This indicates its appropriateness for IWD. However, it seems to be too easy for individuals with mild dementia [66], 
and therefore we do not recommend it without constraints. Moreover, we do not recommend the SFT for IWD, because it comprises tasks such as the arm curl, chair sit-and-reach, back scratch, and 2-min step tests that were deemed unsuitable for IWD (for details please see above).

\section{Recommendations for the use of external cues and walking aids during assessments}

Previous trials assessing motor performance in IWD frequently allowed the use of external cues. However, their influence on results has not yet been well-established. Nevertheless, external cues seem to be important to ensure the feasibility of motor assessments in IWD, and are especially necessary for assessments consisting of many short tasks, such as the TUG [15]. In this context, we note the heterogeneity in external cues applied across previous trials and emphasise the need for standardisation for comparability reasons. Thus, we suggest allowing the exact repetition of instructions but no other external cues, if not otherwise indicated in the assessment protocol. Moreover, we advise a careful documentation and reporting of used external cues. This recommendation of allowing a restricted use of external cues contributes to tailoring motor assessments to specific characteristics of IWD, and is a first step towards standardisation, which needs to be further substantiated. However, the use of external cues is not appropriate for assessments determining complex motor-cognitive performance, such as activities of daily living.

Walking aids are frequently required by both older adults and IWD, and assessment protocols do often not indicate how to deal with them [18]. Despite their influence on detecting gait changes over time [18], we recommend allowing the use of walking aids applied in everyday life due to safety reasons and to avoid missing data. This may also increase ecological validity, since IWD who use a walking aid in everyday life would be examined in their daily situation. Whenever possible, however, the TUG should be performed without walking aids. Focusing on standardisation, we further suggest restricting the use of walking aids to commonly used aids (e.g. walkers, canes, and crutches), which does not include personal assistance. We also recommend carefully documenting and reporting the use of waking aids. Addressing comparability between baseline and post assessment values, additional qualitative analyses may be indicated when considerable changes in the use of walking aids occurred.

\section{Psychometric properties}

Only few investigations examining psychometric properties of motor assessments in IWD were available at the time of the two meetings. Thus, there was no profound empirical basis for evaluating psychometric properties of motor assessments, which emphasises the urgent need for further investigations.

Considering available investigations, validity has been examined too scarcely and heterogeneously to draw comprehensive conclusions. As indicated in Table 4, intraclass correlation coefficient values for recommended assessment tools ranged between .57 and .99, reflecting sufficient relative reliability, whereas higher intra-individual variability shows lower absolute reliability. Based on these findings, it was concluded that the above-recommended assessments show sufficient reliability to assess inter-individual differences in cross sectional or controlled intervention studies, but are not suitable for determining intra-individual changes [15, 20-25, 27-30].

\section{Discussion}

The present article conveys a consensus of recommendations for assessing motor performance in IWD, which was reached during an expert panel with two interrelated one-day meetings at the KIT in December 2014 and February 2015. These recommendations focus on the appropriateness and standardisation of motor assessments for IWD, deal with the use of external cues or walking aids, and consider psychometric properties of recommended assessments.

To appropriately address IWD, we recommend using a sequential approach and suggest a selection of eight motor assessments to investigate balance (FICSIT-4 and GMWT), mobility and gait (TUG, 6-m WT, and instrumented gait analysis), lower limb strength (modified 30-s chair-stand test), and functional performance (Short Physical Performance Battery and Physical Performance Test). Moreover, we put emphasis on a standardised assessment procedure to ensure comparability between different trials/clinical examinations and to thereby allow conclusions to be drawn based on sound evidence. Considering standardisation in general, we advise allowing a restricted use of external cues and walking aids, and to carefully document and report their use. Psychometric properties could not be considered in-depth, but available investigations determined sufficient relative reliability for the majority of recommended assessments. These recommendations were primarily elaborated for research but equally can be applied in clinical practice. However, lower absolute reliability needs to be considered when assessing intra-individual changes.

To our knowledge, this is the first article giving comprehensive recommendations for assessing motor performance in IWD using a qualitative approach. The few available investigations also focusing on 
Table 4 Relative (ICC) and absolute (SEM, MDC95) reliabilities for recommended assessments

\begin{tabular}{|c|c|c|}
\hline \multicolumn{2}{|l|}{ Recommended assessments } & $\begin{array}{l}\text { Test-retest } \\
\text { reliability }^{\text {a }}\end{array}$ \\
\hline \multirow{3}{*}{\multicolumn{2}{|c|}{$\begin{array}{l}\text { Frailty and Injuries: Cooperative Studies } \\
\text { of Intervention Technique - subtest } 4 \text { [37] }\end{array}$}} & ICC $=.79-.82[20]$ \\
\hline & & $\begin{array}{l}\mathrm{SEM}=.55-.60 \\
\text { points }[20]\end{array}$ \\
\hline & & $\begin{array}{l}\mathrm{MDC}_{95}=1.52- \\
1.66 \text { points [20] }\end{array}$ \\
\hline \multirow{6}{*}{$\begin{array}{l}\text { Groningen Meander Walking Test } \\
\text { [27] }\end{array}$} & \multirow[t]{3}{*}{ Time } & $\mathrm{ICC}=.93-.96[27]$ \\
\hline & & $\mathrm{SEM}=1.93 \mathrm{~s}[27]$ \\
\hline & & $\mathrm{MDC}_{95}=5.35 \mathrm{~s}[27]$ \\
\hline & \multirow[t]{3}{*}{ Oversteps } & $\mathrm{ICC}=.57-.79[27]$ \\
\hline & & $\begin{array}{l}\text { SEM }=1.58 \\
\text { oversteps [27] }\end{array}$ \\
\hline & & $\begin{array}{l}\text { MDC }_{95}=4.38 \\
\text { oversteps [27] }\end{array}$ \\
\hline \multicolumn{2}{|l|}{ Berg Balance Scale [40] } & N/A \\
\hline \multicolumn{2}{|c|}{ Performance Oriented Mobility Assessment [41] } & $\mathrm{ICC}=.96[15]$ \\
\hline \multirow{3}{*}{\multicolumn{2}{|c|}{ Timed Up \& Go Test [47] }} & $\begin{array}{l}\text { ICC }=.76-.99 \\
{[20-22,24]^{\mathrm{b}}}\end{array}$ \\
\hline & & $\begin{array}{l}\mathrm{SEM}=1.43-3.03 \mathrm{~s} \\
{[20-22]^{\mathrm{b}}}\end{array}$ \\
\hline & & $\begin{array}{l}\mathrm{MDC}_{95}=2.42-8.07 \mathrm{~s} \\
{[20-22]^{\mathrm{b}}}\end{array}$ \\
\hline \multirow[t]{5}{*}{ 6-m walk test [45] } & Time & $\mathrm{ICC}=.92[24]$ \\
\hline & Speed & $\mathrm{ICC}=.83-.89[20]$ \\
\hline & & $\begin{array}{l}\text { SEM }=.09-.11 \mathrm{~m} / \mathrm{s} \\
{[20]}\end{array}$ \\
\hline & & $\begin{array}{l}\mathrm{MDC}_{95}=.25-.29 \mathrm{~m} / \mathrm{s} \\
{[20]}\end{array}$ \\
\hline & Steps & $\mathrm{ICC}=.80[24]$ \\
\hline \multirow{12}{*}{$\begin{array}{l}\text { Instrumented gait analysis (GAITRite } \\
\text { comfortable pace, single task) [46] }\end{array}$} & Speed & $\mathrm{ICC}=.95-.98$ \\
\hline & & {$[21,25,29]$} \\
\hline & & $\mathrm{SEM}=0.06 \mathrm{~m} / \mathrm{s}[21]$ \\
\hline & & $\begin{array}{l}\mathrm{MDC}_{95}=.11-.13 \mathrm{~m} / \\
{[21,25]}\end{array}$ \\
\hline & \multirow[t]{2}{*}{$\begin{array}{l}\text { Step/ } \\
\text { stride length }\end{array}$} & $\begin{array}{l}\mathrm{ICC}=.97-.98 \\
{[25,29]}\end{array}$ \\
\hline & & $\begin{array}{l}\mathrm{MDC}_{95}=4.15-5.27 \\
8.12-10.24 \mathrm{~cm}[25]\end{array}$ \\
\hline & \multirow[t]{2}{*}{ Step width } & $\mathrm{ICC}=.92-.95[25]$ \\
\hline & & $\begin{array}{l}\mathrm{MDC}_{95}=1.83- \\
2.23 \mathrm{~cm}[25]\end{array}$ \\
\hline & \multirow[t]{2}{*}{$\begin{array}{l}\text { Stance/ } \\
\text { swing time }\end{array}$} & $\begin{array}{l}\mathrm{ICC}=.87-.96 \\
{[25,29]}\end{array}$ \\
\hline & & $\begin{array}{l}\mathrm{MDC}_{95}=.03-.06 \mathrm{~s} \\
{[25]}\end{array}$ \\
\hline & \multirow[t]{2}{*}{ Cadence } & $\begin{array}{l}\text { ICC }=.88-.91 \\
{[25,29]}\end{array}$ \\
\hline & & $\begin{array}{l}\mathrm{MDC}_{95}=7.64- \\
8.13 \mathrm{steps} / \mathrm{min}[25]\end{array}$ \\
\hline
\end{tabular}

Table 4 Relative (ICC) and absolute (SEM, MDC 95 ) reliabilities for recommended assessments (Continued)

\begin{tabular}{|c|c|}
\hline Recommended assessments & $\begin{array}{l}\text { Test-retest } \\
\text { reliability }^{\mathrm{a}}\end{array}$ \\
\hline $\begin{array}{l}\text { Instrumented gait analysis (GAITRite }{ }^{\oplus} \text {, } \\
\text { comfortable pace, dual task) [46] }\end{array}$ & N/A \\
\hline \multirow[t]{3}{*}{ Modified 30-s chair-stand test $[20,55]$} & $\mathrm{ICC}=.79-.88[20]$ \\
\hline & $\begin{array}{l}\mathrm{SEM}=.83-1.52 \\
\text { repetitions [20] }\end{array}$ \\
\hline & $\begin{array}{l}\mathrm{MDC}_{95}=2.30-4.21 \\
\text { repetitions [20] }\end{array}$ \\
\hline Short Physical Performance Battery [63] & $\mathrm{ICC}=.88[28]$ \\
\hline Physical Performance Test [53] & $\mathrm{ICC}=.90[30]$ \\
\hline 2-min walk test [61] & N/A \\
\hline \multirow[t]{3}{*}{ 6-min walk test [62] } & $\begin{array}{l}\text { ICC }=.75-.99 \\
{[21,23]^{\mathrm{b}}}\end{array}$ \\
\hline & $\begin{array}{l}\mathrm{SEM}=19.57- \\
21.86 \mathrm{~m}[21]^{\mathrm{c}}\end{array}$ \\
\hline & $\begin{array}{l}\mathrm{MDC}_{95}=39.76 \mathrm{~m} \\
{[21]^{\mathrm{c}}}\end{array}$ \\
\hline
\end{tabular}

ICC intraclass correlation coefficient, SEM standard error of measurement, $M D C_{95}$ minimal detectable change with $95 \%$ confidence interval a Between-day test-retest reliability, if not otherwise indicated

${ }^{b}$ Between-day and within-day test-retest reliability

'Within-day test-retest reliability

recommendations of motor assessments in IWD analysed assessments used in previous trials from a quantitative perspective, and did not deal with standardisation of assessment procedures or tailoring assessments to specific characteristics of IWD. For the most part, the assessments recommended in this paper coincide with these recommendations (see Bossers et al. [19] and McGough et al. [31]).

A major strength of the expert panel was the comprehensive and thorough analysis of the appropriateness of motor assessments considering specific characteristics of IWD. Following the expert panel, the recommended assessments were applied in a trial of our own with IWD in mild to moderate stages of the disease [67] and demonstrated feasibility. This is in line with previous investigations successfully utilising these assessments or determining their reliability. Nevertheless, information on psychometric properties in many cases is still insufficient and further research is needed [19]. Furthermore, our own experiences showed that it was not possible to identically adopt assessment procedures common for healthy older adults for IWD. For example, it was necessary to allow external cues in form of repeated instructions. This clearly illustrates the need for tailored versions of existing motor assessments, which first need to be standardised and evaluated. Unfortunately, it was not possible to discuss more recent findings within another expert meeting. 
Potential biases need to be stated concerning the choice of motor assessments. Despite applying a systematic approach, considered assessments were restricted to those utilised in randomised controlled trials with IWD. Thus, other potentially appropriate assessments may be missing. Additionally, the derived recommendations could be biased by the researchers' experiences and preferences. Moreover, this article only considers existing assessments used in previous trials, whereby the recommendations only include the most suitable of the available possibilities. Besides investigating psychometric properties of existing assessments and developing tailored standardised versions, which consider specific characteristics of IWD, future research should also focus on developing new assessments specifically for IWD. In summary, the recommendations in this article were thoroughly deduced from existing literature and consider the psychometric properties as much as possible. However, they should be used carefully as it is important to first evaluate them in different studies with IWD and address further questions due to limited evidence.

\section{Conclusions}

This article contributes to giving recommendations on performing motor assessments in IWD. However, these recommendations show a preliminary character and are not able to deal with all existing questions. One main problem is that most assessments applied in previous trials were not developed initially for IWD and are not well-investigated within this target population.

Finally, we indicate the need for further studies investigating common motor assessments for administration in IWD. We further encourage tailoring assessment procedures and evaluating existing motor assessments according to the special characteristics of IWD, and then investigating these adapted versions. Nevertheless, it will be important to develop and investigate specific assessments specifically for IWD, such as the GMWT.

In line with Gonçalves et al. [4], we encourage scientists and clinical practitioners to reach a consensus concerning the use of motor assessments, and to apply a standardised assessment procedure aiming to enhance comparability in the research field and clinical practice. With regard to scientific publications, we therefore ask scientists to give a detailed report on how they perform motor assessments in IWD, as different modifications exist and it is often not clear which has been applied.

All efforts undertaken to develop and apply standardised and reliable motor assessments which are appropriate and meaningful for IWD are important steps to enhance evidence concerning efficacy and effectiveness of physical activity on motor performance in IWD.

\section{Abbreviations}

FICSIT-4: Frailty and Injuries: Cooperative Studies of Intervention Technique subtest 4; GMWT: Groningen Meander Walking Test; IWD: individuals with dementia; KIT: Karlsruhe Institute of Technology; SFT: Senior Fitness Test; STS: sit-to-stand; TUG: Timed Up \& Go Test; WT: walk test, walk tests

\section{Acknowledgements}

We would like to thank Prof. Dr. Dr. h.c. em. Klaus Willimczik for participating in the expert panel and supporting the guidance of the discussion, Dr. Tim Fleiner for participating as well as presenting an experience report regarding daily and research work with IWD, and Lisa Peterson for her linguistic assistance on behalf of the authors.

We acknowledge support by Deutsche Forschungsgemeinschaft and Open Access Publishing Fund of Karlsruhe Institute of Technology.

\section{Funding}

This project is financially supported by the Dietmar Hopp Stiftung (St. Leon-Rot, Germany). The sponsor does not have any role in the design of the study, neither in its execution, the collection, analysis, or interpretation of data, the decision to submit results, nor in writing the report.

\section{Availability of data and materials}

Not applicable.

\section{Authors' contributions}

ST, ASC and AW prepared the expert panel. ST and SS extensively discussed existing motor assessments and their performance in preparation of the expert panel. ST, ASC, WB, MM, TS, KB, AST, CN, SA, RW, and AW participated in the expert panel. ST, ASC, MM, and WB gave presentations within the expert panel. All authors contributed to the development of the assessment battery and further recommendations. ST and BB wrote the manuscript. All authors provided critical feedback and approved the final manuscript.

\section{Authors' information}

$\mathrm{ST}, \mathrm{BB}, \mathrm{ASC}, \mathrm{WB}, \mathrm{MM}$, and AW performed comprehensive research with IWD and are familiar in working with the target group. ST and WB intensively analysed literature towards research on motor assessments in IWD. WB, SS, $T S, K B, C N, S A$, and AW acquired expertise in developing and evaluating motor assessments for various populations. ST, BB, ASC, WB, MM, SS, KB, AST, RW, and AW were involved in ageing research. ST, BB, ASC, WB, MM, TS, AST, and AW studied the effects of exercise on cognition and brain plasticity.

Ethics approval and consent to participate

Not applicable.

\section{Consent for publication}

Not applicable.

\section{Competing interests}

The authors declare that they have no competing interests.

\section{Publisher's Note}

Springer Nature remains neutral with regard to jurisdictional claims in published maps and institutional affiliations.

\section{Author details}

${ }^{1}$ Institute of Sports and Sports Science, Karlsruhe Institute of Technology, Engler-Bunte-Ring 15, 76131 Karlsruhe, Germany. ${ }^{2}$ Center for Human Movement Sciences, University Medical Center Groningen, University of Groningen, Groningen, The Netherlands. ${ }^{3}$ Centre for Clinical Research, University of Queensland, Brisbane, Australia. ${ }^{4}$ Department of Neurology, Greifswald University Medicine, Greifswald, Germany. ${ }^{5}$ Department of Sport Science and Sport, Friedrich-Alexander University Erlangen-Nürnberg, Erlangen, Germany. ${ }^{6}$ Unit of Experimental Psychiatry, Department of Psychiatry, Perelman School of Medicine at the University of Pennsylvania, Philadelphia, USA. 'Institute of Physiology, Charité - Universitätsmedizin Berlin, a corporate member of Freie Universität Berlin, Humboldt-Universität zu Berlin, and Berlin Institute of Health, Berlin, Germany. 
Received: 19 December 2018 Accepted: 31 March 2019 Published online: 13 April 2019

\section{References}

1. Ahlskog JE, Geda YE, Graff-Radford NR, Petersen RC. Physical exercise as a preventive or disease-modifying treatment of dementia and brain aging. Mayo Clin Proc. 2011;86:876-84. https://doi.org/10.4065/mcp.2011.0252.

2. Hauer $K$, Becker $C$, Lindemann U, Beyer N. Effectiveness of physical training on motor performance and fall prevention in cognitively impaired older persons: a systematic review. Am J Phys Med Rehabil. 2006;85:847-57. https://doi.org/10.1097/01.phm.0000228539.99682.32.

3. Brett L, Traynor V, Stapley P. Effects of physical exercise on health and wellbeing of individuals living with a dementia in nursing homes: a systematic review. J Am Med Dir Assoc. 2016;17:104-16. https://doi.org/10.1016/j.jamda. 2015.08.016.

4. Gonçalves A-C, Cruz J, Marques A, Demain S, Samuel D. Evaluating physical activity in dementia: a systematic review of outcomes to inform the development of a core outcome set. Age Ageing. 2018;47:34-41. https:// doi.org/10.1093/ageing/afx135.

5. Fox B, Henwood T, Keogh J, Neville C. Psychometric viability of measures of functional performance commonly used for people with dementia: a systematic review of measurement properties. JBI Database System Rev Implement Rep. 2016;14:115-71. https://doi.org/10.11124/JBISRIR-2016-003064.

6. Baddeley A, Logie R, Bressi S, Della Sala S, Spinnler H. Dementia and working memory. Q J Exp Psychol A. 1986;38:603-18. https://doi.org/10. 1080/14640748608401616.

7. Perry RJ, Hodges JR. Attention and executive deficits in Alzheimer's disease. A critical review. Brain. 1999;122:383-404. https://doi.org/10. 1093/brain/122.3.383.

8. Allan LM, Ballard CG, Burn DJ, Kenny RA. Prevalence and severity of gait disorders in Alzheimer's and non-Alzheimer's dementias. J Am Geriatr Soc. 2005;53:1681-7. https://doi.org/10.1111/j.1532-5415.2005.53552.x.

9. Manckoundia P, Mourey F, Pfitzenmeyer P, Papaxanthis C. Comparison of motor strategies in sit-to-stand and back-to-sit motions between healthy and Alzheimer's disease elderly subjects. Neuroscience. 2006;137:385-92. https://doi.org/10.1016/j.neuroscience.2005.08.079.

10. van lersel MB, Hoefsloot W, Munneke M, Bloem BR, Olde Rikkert MGM Systematic review of quantitative clinical gait analysis in patients with dementia. Z Gerontol Geriatr. 2004;37:27-32. https://doi.org/10.1007/s00391004-0176-7.

11. Hauer $K$, Oster P. Measuring functional performance in persons with dementia. J Am Geriatr Soc. 2008;56:949-50. https://doi.org/10.1111/j.15325415.2008.01649.x.

12. Mancini M, Horak FB. The relevance of clinical balance assessment tools to differentiate balance deficits. Eur J Phys Rehabil Med. 2010;46:239-48.

13. Zijlstra W, Aminian K. Mobility assessment in older people: new possibilities and challenges. Eur J Ageing. 2007;4:3-12. https://doi.org/10.1007/s10433007-0041-9.

14. Rockwood K, Awalt E, Carver D, Macknight C. Feasibility and measurement properties of the functional reach and the timed up and go tests in the Canadian study of health and aging. J Gerontol Ser A Biol Med Sci. 2000;55: M70-3. https://doi.org/10.1093/gerona/55.2.M70.

15. van lersel MB, Benraad CEM, Olde Rikkert MGM. Validity and reliability of quantitative gait analysis in geriatric patients with and without dementia. J Am Geriatr Soc. 2007;55:632-4. https://doi.org/10.1111/j.1532-5415.2007. 01130.x.

16. Hajek A, Brettschneider C, Posselt T, Lange C, Mamone S, Wiese B, et al. Predictors of frailty in old age - results of a longitudinal study. J Nutr Health Aging. 2016;20:952-7. https://doi.org/10.1007/s12603-015-0634-5.

17. Suttanon P, Hill KD, Said CM, Logiudice D, Lautenschlager NT, Dodd KJ. Balance and mobility dysfunction and falls risk in older people with mild to moderate Alzheimer disease. Am J Phys Med Rehabil. 2012;91:12-23. https://doi.org/10.1097/PHM.0b013e31823caeea.

18. Schwenk M, Schmidt M, Pfisterer M, Oster P, Hauer K. Rollator use adversely impacts on assessment of gait and mobility during geriatric rehabilitation. J Rehabil Med. 2011;43:424-9. https://doi.org/10.2340/16501977-0791.

19. Bossers WJR, van der Woude, Lucas HV, Boersma F, Scherder EJA, Heuvelen $\checkmark$, Marieke JG. Recommended measures for the assessment of cognitive and physical performance in older patients with dementia: a systematic review. Dement Geriatr Cogn Dis Extra. 2012;2:589-609. https://doi.org/10.1159/ 000345038.
20. Blankevoort CG, Heuvelen v, Marieke JG, Scherder EJA. Reliability of six physical performance tests in older people with dementia. Phys Ther. 2013;93:69-78. https://doi.org/10.2522/ptj.20110164.

21. Ries JD, Echternach JL, Nof L, Gagnon Blodgett M. Test-retest reliability and minimal detectable change scores for the timed "up \& go" test, the six-minute walk test, and gait speed in people with Alzheimer disease. Phys Ther. 2009;89: 569-79. https://doi.org/10.2522/ptj.20080258.

22. Suttanon P, Hill KD, Dodd KJ, Said CM. Retest reliability of balance and mobility measurements in people with mild to moderate Alzheimer's disease. Int Psychogeriatr. 2011;23:1152-9. https://doi.org/10.1017/S1041610211000639.

23. Tappen RM, Roach KE, Buchner D, Barry C, Edelstein J. Reliability of physical performance measures in nursing home residents with Alzheimer's disease. J Gerontol A Biol Sci Med Sci. 1997;52:M52-5. https:// doi.org/10.1093/gerona/52A.1.M52.

24. Thomas VS, Hageman PA. A preliminary study on the reliability of physical performance measures in older day-care center clients with dementia. Int Psychogeriatr. 1999;14:17-23. https://doi.org/10.1017/\$1041610202008244.

25. Wittwer JE, Webster KE, Andrews PT, Menz HB. Test-retest reliability of spatial and temporal gait parameters of people with Alzheimer's disease. Gait Posture. 2008;28:392-6. https://doi.org/10.1016/j.gaitpost.2008.01.007.

26. Alencar MA, Dias JMD, Figueiredo LC, Dias RC. Handgrip strength in elderly with dementia: study of reliability. Rev Bras Fisioter. 2012;16:510-4. https:// doi.org/10.1590/S1413-35552012005000059.

27. Bossers WJR, van der Woude, Lucas HV, Boersma F, Scherder EJA, Heuvelen V, Marieke JG. The Groningen meander walking test: a dynamic walking test for older adults with dementia. Phys Ther. 2014;94:262-72. https://doi.org/10.2522/ ptj.20130077.

28. Fox B, Henwood T, Neville C, Keogh J. Relative and absolute reliability of functional performance measures for adults with dementia living in residential aged care. Int Psychogeriatr. 2014;26:1659-67. https://doi.org/ 10.1017/S1041610214001124.

29. McGough EL, Logsdon RG, Kelly VE, Teri L. Functional mobility limitations and falls in assisted living residents with dementia: physical performance assessment and quantitative gait analysis. J Geriatr Phys Ther. 2013;36:78-86. https://doi.org/10. 1519/JPT.0b013e318268de7f.

30. Farrell MK, Rutt RA, Lusardi MM, Williams AK. Reliability of the physical performance test in people with dementia. Phys Occup Ther Geriatr. 2010;28: 144-53. https://doi.org/10.3109/02703181.2010.487973.

31. McGough EL, Lin S-Y, Belza B, Becofsky KM, Jones DL, Liu M, et al. A scoping review of physical performance outcome measures used in exercise interventions for older adults with Alzheimer disease and related dementias. J Geriatr Phys Ther. 2019;42:28-47. https://doi.org/10.1519/JPT.0000000000000159.

32. Scharpf A, Servay S, Woll A. Auswirkungen von körperlicher Aktivität auf demenzielle Erkrankungen. Sportwiss. 2013;43:166-80. https://doi.org/10. 1007/s12662-013-0295-7.

33. Bossers WJR, Scherder EJA, Boersma F, Hortobagyi T, van der Woude, Lucas HV, Heuvelen v, Marieke JG. Feasibility of a combined aerobic and strength training program and its effects on cognitive and physical function in institutionalized dementia patients. A pilot study. PLoS One. 2014;9:e97577. https://doi.org/10.1371/journal.pone.0097577.

34. Bossers WJR, van der Woude, Lucas HV, Boersma F, Hortobagyi T, Scherder EJA, Heuvelen v, Marieke JG. A 9-week aerobic and strength training program improves cognitive and motor function in patients with dementia: a randomized, controlled trial. Am J Geriatr Psychiatry. 2015;23:1106-16. https:// doi.org/10.1016/j.jagp.2014.12.191.

35. Bossers WJR, van der Woude, Lucas HV, Boersma F, Hortobagyi T, Scherder EJA, Heuvelen V, Marieke JG. Comparison of effect of two exercise programs on activities of daily living in individuals with dementia: a 9-week randomized, controlled trial. J Am Geriatr Soc. 2016;64:1258-66. https://doi.org/10.1111/jgs.14160.

36. Vellas BJ, Rubenstein LZ, Ousset PJ, Faisant C, Kostek V, Nourhashemi F, et al. One-leg standing balance and functional status in a population of 512 community-living elderly persons. Aging Clin Exp Res. 1997;9:95-8. https:// doi.org/10.1007/BF03340133.

37. Rossiter-Fornoff JE, Wolf SL, Wolfson LI, Buchner DM. A cross-sectional validation study of the FICSIT common Data Base static balance measures. J Gerontol Ser A Biol Med Sci. 1995;50A:M291-7. https://doi.org/10.1093/ gerona/50A.6.M291.

38. Duncan PW, Weiner DK, Chandler J, Studenski S. Functional reach: a new clinical measure of balance. J Gerontol. 1990;45:M192-7. https://doi.org/10. 1093/geronj/45.6.M192. 
39. Johansson G, Jarnlo G-B. Balance training in 70-year-old women. Physiother Theory Pract. 2009;7:121-5. https://doi.org/10.3109/09593989109106962.

40. Berg K. Measuring balance in the elderly: preliminary development of an instrument. Physiother Can. 1989;41:304-11. https://doi.org/10.3138/ptc.41.6.304.

41. Tinetti ME. Performance-oriented assessment of mobility problems in elderly patients. J Am Geriatr Soc. 1986;34:119-26. https://doi.org/10.1111/j.15325415.1986.tb05480.x

42. Ruhe A, Fejer R, Walker B. The test-retest reliability of Centre of pressure measures in bipedal static task conditions - a systematic review of the literature. Gait Posture. 2010;32:436-45. https://doi.org/10.1016/j.gaitpost. 2010.09.012.

43. Allan LM, Ballard CG, Rowan EN, Kenny RA. Incidence and prediction of falls in dementia: a prospective study in older people. PLoS One. 2009;4:e5521. https://doi.org/10.1371/journal.pone.0005521.

44. Mathias S, Nayak US, Isaacs B. Balance in elderly patients: the "get-up and go" test. Arch Phys Med Rehabil. 1986;67:387-9.

45. Guralnik JM, Seeman TE, Tinetti ME, Nevitt MC, Berkman LF. Validation and use of performance measures of functioning in a non-disabled older population: MacArthur studies of successful aging. Aging (Milano). 1994;6: 410-9. https://doi.org/10.1007/BF03324272.

46. Kressig RW, Beauchet O. Guidelines for clinical applications of spatiotemporal gait analysis in older adults. Aging Clin Exp Res. 2006;18:174-6. https://doi.org/10.1007/BF03327437.

47. Podsiadlo D, Richardson S. The timed "up \& go": a test of basic functional mobility for frail elderly persons. J Am Geriatr Soc. 1991;39:142-8. https:// doi.org/10.1111/j.1532-5415.1991.tb01616.x.

48. Muir SW, Speechley M, Wells J, Borrie M, Gopaul K, Montero-Odasso M. Gait assessment in mild cognitive impairment and Alzheimer's disease: the effect of dual-task challenges across the cognitive spectrum. Gait Posture. 2012;35: 96-100. https://doi.org/10.1016/j.gaitpost.2011.08.014

49. Montero-Odasso M, Verghese J, Beauchet O, Hausdorff JM. Gait and cognition: a complementary approach to understanding brain function and the risk of falling. J Am Geriatr Soc. 2012;60:2127-36. https://doi.org/10. 1111/j.1532-5415.2012.04209.x.

50. Sterke CS, van Beeck EF, Looman CWN, Kressig RW, van der Cammen, Tischa JM. An electronic walkway can predict short-term fall risk in nursing home residents with dementia. Gait Posture. 2012;36:95-101. https://doi. org/10.1016/j.gaitpost.2012.01.012.

51. Verghese J, Wang C, Lipton RB, Holtzer R, Xue X. Quantitative gait dysfunction and risk of cognitive decline and dementia. J Neurol Neurosurg Psychiatry. 2007;78:929-35. https://doi.org/10.1136/jnnp.2006.106914.

52. Csuka M, McCarty DJ. Simple method for measurement of lower extremity muscle strength. Am J Med. 1985;78:77-81. https://doi.org/10.1016/0002 9343(85)90465-6.

53. Reuben DB, Siu AL. An objective measure of physical function of elderly outpatients. J Am Geriatr Soc. 1990;38:1105-12. https://doi.org/10.1111/j. 1532-5415.1990.tb01373.x.

54. Rikli RE, Jones CJ. Senior fitness test manual - updated edition. Champaign: Human Kinetics; 2006

55. Jones CJ, Rikli RE, Beam WC. A 30-s chair-stand test as a measure of lower body strength in community-residing older adults. Res Q Exerc Sport. 1999; 70:113-9. https://doi.org/10.1080/02701367.1999.10608028.

56. McCarthy EK, Horvat MA, Holtsberg PA, Wisenbaker JM. Repeated chair stands as a measure of lower limb strength in sexagenarian women. J Gerontol A Biol Sci Med Sci. 2004;59:1207-12. https://doi.org/10.1093/ gerona/59.11.1207

57. Lord SR, Murray SM, Chapman K, Munro B, Tiedemann A. Sit-to-stand performance depends on sensation, speed, balance, and psychological status in addition to strength in older people. J Gerontol A Biol Sci Med Sci. 2002;57:M539-43. https://doi.org/10.1093/gerona/57.8.M539.

58. Janssen WGM, Bussmann HBJ, Stam HJ. Determinants of the sit-to-stand movement: a review. Phys Ther. 2002;82:866-79. https://doi.org/10.1093/ ptj/82.9.866

59. Bean JF, Kiely DK, LaRose S, Alian J, Frontera WR. Is stair climb power a clinically relevant measure of leg power impairments in at-risk older adults? Arch Phys Med Rehabil. 2007;88:604-9. https://doi.org/10.1016/j.apmr.2007.02.004.

60. Netz Y, Ayalon M, Dunsky A, Alexander N. 'The multiple-sit-to-stand' field test for older adults: what does it measure? Gerontology. 2004;50:121-6. https://doi.org/10.1159/000076769.

61. Cooper KH. A means of assessing maximal oxygen intake. JAMA. 1968;203: 201. https://doi.org/10.1001/jama.1968.03140030033008.
62. Enright PL. The six-minute walk test. Respir Care. 2003;48:783-5

63. Guralnik JM, Simonsick EM, Ferrucci L, Glynn RJ, Berkman LF, Blazer DG, et al. A short physical performance battery assessing lower extremity function: association with self-reported disability and prediction of mortality and nursing home admission. J Gerontol. 1994;49:M85-94. https://doi.org/10.1093/geronj/49.2.M85.

64. Graessel E, Viegas R, Stemmer R, Kuchly B, Kornhuber J, Donath C. The Erlangen test of activities of daily living: first results on reliability and validity of a short performance test to measure fundamental activities of daily living in dementia patients. Int Psychogeriatr. 2009;21:103-12. https://doi.org/10.1017/ S1041610208007710.

65. Freiberger E, de Vreede P, Schoene D, Rydwik E, Mueller V, Frandin K, HopmanRock M. Performance-based physical function in older community-dwelling persons: a systematic review of instruments. Age Ageing. 2012;41:712-21. https://doi.org/10.1093/ageing/afs099.

66. Luttenberger K, Schmiedeberg A, Grassel E. Activities of daily living in dementia: revalidation of the E-ADL test and suggestions for further development. BMC Psychiatry. 2012;12:208. https://doi.org/10.1186/1471-244X-12-208.

67. Trautwein S, Scharpf A, Barisch-Fritz B, Niermann C, Woll A. Effectiveness of a 16-Week Multimodal Exercise Program on Individuals With Dementia: Study Protocol for a Multicenter Randomized Controlled Trial. JMIR Res Protoc. 2017;6:e35. https://doi.org/10.2196/resprot.6792.

68. Rolland Y, Pillard F, Klapouszczak A, Reynish E, Thomas D, Andrieu S, et al. Exercise program for nursing home residents with Alzheimer's disease: a 1-year randomized, controlled trial. J Am Geriatr Soc. 2007;55:158-65. https://doi.org/10. 1111/j.1532-5415.2007.01035.X.

69. Burgener SC, Yang Y, Gilbert R, Marsh-Yant S. The effects of a multimodal intervention on outcomes of persons with early-stage dementia. Am J Alzheimers Dis Other Dement. 2008;23:382-94. https://doi.org/10.1177/ 1533317508317527.

70. Toulotte C. Effects of physical training on the physical capacity of frail, demented patients with a history of falling: a randomised controlled trial. Age Ageing. 2003;32:67-73. https://doi.org/10.1093/ageing/32.1.67.

71. Netz Y, Axelrad S, Argov E. Group physical activity for demented older adults feasibility and effectiveness. Clin Rehabil. 2007;21:977-86. https://doi. org/10.1177/0269215507078318.

72. Christofoletti G, Oliani MM, Gobbi S, Stella F, Bucken Gobbi LT, Renato Canineu P. A controlled clinical trial on the effects of motor intervention on balance and cognition in institutionalized elderly patients with dementia. Clin Rehabil. 2008;22:618-26. https://doi.org/10.1177/0269215507086239.

73. Fajersztajn L, Cordeiro RC, Andreoni S, Garcia JT. Effects of functional physical activity on the maintenance of motor function in Alzheimer's disease. Dement neuropsychol. 2008;2:233-40. https://doi.org/10.1590/S198057642009DN20300013.

74. Hauer K, Schwenk M, Zieschang T, Essig M, Becker C, Oster P. Physical training improves motor performance in people with dementia: a randomized controlled trial. J Am Geriatr Soc. 2012;60:8-15. https://doi.org/ 10.1111/j.1532-5415.2011.03778.x.

75. Santana-Sosa E, Barriopedro MI, Lopez-Mojares LM, Perez M, Lucia A. Exercise training is beneficial for Alzheimer's patients. Int J Sports Med. 2008;29:845-50. https://doi.org/10.1055/s-2008-1038432.

76. Lundin-Olsson L, Nyberg L, Gustafson Y. Attention, frailty, and falls: the effect of a manual task on basic mobility. J Am Geriatr Soc. 1998;46:758-61. https://doi.org/10.1111/j.1532-5415.1998.tb03813.x.

77. Shumway-Cook A, Brauer S, Woollacott M. Predicting the probability for falls in community-dwelling older adults using the timed up \& go test. Phys Ther. 2000;80:896-903. https://doi.org/10.1093/ptj/80.9.896.

78. Bessou P, Dupui $P$, Montoya R, Pagès B. Simultaneous recording of longitudinal displacements of both feet during human walking. J Physiol Paris. 1988:83:102-10.

79. Kemoun G, Thibaud M, Roumagne N, Carette P, Albinet C, Toussaint L, et al. Effects of a physical training programme on cognitive function and walking efficiency in elderly persons with dementia. Dement Geriatr Cogn Disord. 2010;29:109-14. https://doi.org/10.1159/000272435.

80. Verkerke GJ, Lemmink KAPM, Slagers AJ, Westhoff MH, van Riet GAJ, Rakhorst G. Precision, comfort and mechanical performance of the Quadriso-tester, a quadriceps force measuring device. Med Biol Eng Comput. 2003;41:283-9. https://doi.org/10.1007/BF02348432.

81. Cott CA, Dawson P, Sidani S, Wells D. The effects of a walking/talking program on communication, ambulation, and functional status in residents with Alzheimer disease. Alzheimer Dis Assoc Disord. 2002;16:81-7. https:// doi.org/10.1097/00002093-200204000-00005. 
82. Venturelli M, Scarsini R, Schena F. Six-month walking program changes cognitive and ADL performance in patients with Alzheimer. Am J Alzheimers Dis Other Dement. 2011;26:381-8. https://doi.org/10.1177/ 1533317511418956.

83. Tappen RM, Roach KE, Applegate EB, Stowell P. Effect of a combined walking and conversation intervention on functional mobility of nursing home residents with Alzheimer disease. Alzheimer Dis Assoc Disord. 2000;14:196-201.

Ready to submit your research? Choose BMC and benefit from:

- fast, convenient online submission

- thorough peer review by experienced researchers in your field

- rapid publication on acceptance

- support for research data, including large and complex data types

- gold Open Access which fosters wider collaboration and increased citations

- maximum visibility for your research: over $100 \mathrm{M}$ website views per year

At $B M C$, research is always in progress.

Learn more biomedcentral.com/submissions 